Article

\title{
Transcriptome Analysis of Bursaphelenchus xylophilus Uncovers the Impact of Stenotrophomonas maltophilia on Nematode and Pine Wilt Disease
}

\author{
Qi Xue ${ }^{1,2}$, Xiao-Qin $W u^{1,2, * \mathbb{D}}$, Fei $W^{1,2}$ and Jian-Ren Ye ${ }^{1,2}$ \\ 1 Co-Innovation Center for Sustainable Forestry in Southern China, College of Forestry, \\ Nanjing Forestry University, Nanjing 210037, Jiangsu, China; xq2159@163.com (Q.X.); \\ wufeinjfu@sina.com (F.W.); jrye@njfu.edu.cn (J.-R.Y.) \\ 2 Jiangsu Key Laboratory for Prevention and Management of Invasive Species, Nanjing Forestry University, \\ Nanjing 210037, Jiangsu, China \\ * Correspondence: xqwu@njfu.edu.cn; Tel.: +86-25-8542-7427
}

Received: 15 June 2020; Accepted: 18 August 2020; Published: 20 August 2020

\begin{abstract}
Stenotrophomonas maltophilia influences the reproduction, pathogenicity, and gene expression of aseptic Bursaphelenchus xylophilus after inoculation of aseptic Pinus massoniana. Pine wilt disease is a destructive pine forest disease caused by $B$. xylophilus, and its pathogenesis is unclear. The role of bacteria associated with B. xylophilus in pine wilt disease has attracted widespread attention. S. maltophilia is one of the most dominant bacteria in B. xylophilus, and its effect is ambiguous. This study aims to explore the role of $S$. maltophilia in pine wilt disease. The reproduction and virulence of aseptic B. xylophilus and B. xylophilus containing S. maltophilia were examined by inoculating aseptic P. massoniana seedlings. The gene expressions of two nematode treatments were identified by transcriptome sequencing. The reproduction and virulence of B. xylophilus containing S. maltophilia were stronger than that of aseptic nematodes. There were 4240 differentially expressed genes between aseptic B. xylophilus and B. xylophilus containing S. maltophilia after inoculation of aseptic P. massoniana, including 1147 upregulated genes and 2763 downregulated genes. These differentially expressed genes were significantly enriched in some immune-related gene ontology (GO) categories, such as membrane, transporter activity, metabolic processes, and many immune-related pathways, such as the wnt, rap1, PI3K-Akt, cAMP, cGMP-PKG, MAPK, ECM-receptor interaction, and calcium signaling pathways. The polyubiquitin-rich gene, leucine-rich repeat serine/threonine-protein kinase gene, glyceraldehyde-3-phosphate dehydrogenase (GAPDH) gene, acetyl-CoA carboxylase gene, and heat shock protein genes were the key genes associated with immune resistance. Moreover, there were four cell wall hydrolase genes, thirty-six detoxification- and pathogenesis-related protein genes, one effector gene and ten cathepsin L-like cysteine proteinase genes that were differentially expressed. After inoculation of the host pine, S. maltophilia could affect the virulence and reproduction of B. xylophilus by regulating the expression of parasitic, immune, and pathogenicity genes of B. xylophilus.
\end{abstract}

Keywords: Bursaphelenchus xylophilus; Stenotrophomonas maltophilia; Pinus massoniana; differentially expressed genes; virulence

\section{Introduction}

Pine wilt disease (PWD) is a devastating disease in pines caused by the pine wood nematode (PWN), Bursaphelenchus xylophilus. It is native to North America [1], and epidemic in East Asian (China, Japan, and Korea) [2-4], causing serious ecological damage and economic loss. Since PWD was reported in 1982 in Nanjing, China, it has spread to 18 provinces with an area of more than 1.1 million hm², and more 
than 80 million pine trees have wilted completely [5]. The occurrence and development of the disease involve many factors, such as susceptible pine hosts, a beetle vector, the nematode, associated bacteria and fungi, and the appropriate geographical environment. The pathogenesis of PWD is not clear $[4,6]$.

A large number of bacteria can adhere to the surface of B. xylophilus, some of them are random [7-9]. The species of bacteria associated with B. xylophilus from different regions and habitats are different $[6,10]$. Pseudomonas were dominant strains in PWNs isolated in China, but Bacillus were dominant in Japan and both genera were dominant in Korea [11]. Ewingella americana, Pseudomonas fluorescens, and Pantoea agglomerans are present in PWN obtained from different Pinus spp. with distinct geographical locations. Agrobacterium sp., Bordetella sp., and Fusobacterium sp. seem to be particular associated to PWN when cultured in fungus [6]. PWN-Associated bacteria may have putative important effect in PWD. Some PWN-associated bacteria can secrete cellulase, which is extremely important for nematode colonization [12]. Serratia spp. may assist the nematode opportunistically under the oxidative stress (OS) resistant in the disease [13]. Stenotrophomonas have an important role in $\alpha$-pinene degradation, which may represent a major protective role in pine defenses [14].

Compared with the surface environment, the internal environment of B. xylophilus is relatively stable. Yuan et al. found that the bacteria associated with PWN not only existed on PWN's surface, but also inside of the PWN [15]. The bacteria in B. xylophilus from different regions and pine species mainly belong to Stenotrophomonas, Achromatopsia, Ewingella, Leifsonia, Rhizobia, and Pseudomonas [15]. Additionally, relatively abundant bacteria in B. xylophilus from different host pine trees were also found to be Stenotrophomonas, Pseudomonas, and Elizabethkingia [16]. Furthermore, the dominant bacterium in B. xylophilus individuals with different virulence was Stenotrophomonas, followed by Pseudomonadaceae_unclassified and Rhizobiaceae_unclassified [17]. Stenotrophomonas was also abundant in propagative B. xylophilus [18]. Eighty percent of culturable bacteria in B. xylophilus isolated from Pinus massoniana were S. maltophilia and A. xylosoxidans [19]. Thus, it can be seen that S. maltophilia is one of the most dominant bacteria in the B. xylophilus.

After treatment with $S$. maltophilia, the reproduction of B. xylophilus cultured on Botrytis cinerea decreased, while the virulence of B. xylophilus increased [20]. He et al. analyzed the genes in aseptic B. xylophilus and B. xylophilus carrying S. maltophilia cultured on B. cinerea by transcriptome sequencing and found that a number of reproduction-related genes were downregulated, but many pathogenesis-related genes were upregulated in B. xylophilus carrying S. maltophilia compared with aseptic B. xylophilus [21]. B. xylophilus has mycetophagous and phytophagous feeding stages in its life cycle. The nematode feeds on epithelial cells and living parenchyma in living host trees and starts to reproduce. After inoculating pine trees, the reproduction of B. xylophilus carrying S. maltophilia was lower than that of aseptic B. xylophilus. This phenomenon was opposite to that in the individuals cultured on $B$. cinerea. Therefore, according to a previous study reference on nematodes cultured on B. cinerea, it is not yet possible to define the role of $S$. maltophilia in the interaction between B. xylophilus and pine trees.

For this purpose, the propagative capacity and virulence of aseptic nematodes and nematodes with S. maltophilia inoculated into aseptic pine seedlings were examined in this study. Transcriptome sequencing of aseptic nematodes and nematodes with S. maltophilia was carried out after inoculation to explore the molecular mechanism by which $S$. maltophilia affects the propagation and virulence of the B. xylophilus. The above results will be helpful in revealing the contribution of $S$. maltophilia to PWD and provide a reference for further exploring the mechanism of PWD.

\section{Materials and Methods}

\subsection{Biological Materials}

The B. xylophilus strain (AMA3) was isolated from pinewood chips of infested P. massoniana in Maanshan, Anhui, China. S. maltophilia (NSPmBx03) was the bacterium inside B. xylophilus extracted from infected P. massoniana in Nanjing, Jiangsu, China [18]. Nematodes and bacteria were kept in 
the Jiangsu Key Laboratory for Prevention and Management of Invasive Species, Nanjing Forestry University, Nanjing, Jiangsu, China.

\subsection{Preparation of Aseptic B. xylophilus}

Nematodes were cultured on $B$. cinerea grown on potato dextrose agar (PDA) at $25^{\circ} \mathrm{C}$ for 5 days and collected with a Baermann funnel [22]. The nematode suspension $(1.5 \mathrm{~mL})$ was poured into a petri dish (2-3 cm diam.) at $25^{\circ} \mathrm{C}$ for laying eggs. After $4-6 \mathrm{~h}$, eggs were seen adhering to the Petri dish. Sterile water was added to the Petri dish to discard the nematodes, while the eggs were retained. Fresh $15 \% \mathrm{H}_{2} \mathrm{O}_{2}$ was used to asepticize the eggs for $1 \mathrm{~h}$. The bacteria-free eggs were transferred to PDA plates cultured with $B$. cinerea for 5 days. The propagated nematodes were collected under aseptic conditions and stored at $4{ }^{\circ} \mathrm{C}$ [23]. At the same time, $1 \mathrm{~mL}$ of nematode solution was added to Luria-Bertani (LB) medium and cultured at $25^{\circ} \mathrm{C}$ for 3 days to test whether the prepared nematodes were carrying bacteria. Clear LB medium was an indication that aseptic PWNs (Bx_a) had been obtained.

\subsection{Preparation of B. xylophilus Treated with S. maltophilia}

A colony of S. maltophilia was cultured in an Erlenmeyer flask of $50 \mathrm{~mL}$ of LB medium at $28^{\circ} \mathrm{C}$ and $200 \mathrm{rpm}$ for $24 \mathrm{~h}$. The concentration of S. maltophilia was adjusted to $8.0 \times 10^{8} \mathrm{CFUs}$ (colony-forming units), and $200 \mu \mathrm{L}$ of this suspension was sprayed onto PDA plates containing B. cinerea. Each plate was inoculated with 1000 bacteria-free nematodes and incubated for 5 days at $25^{\circ} \mathrm{C}$. The propagated nematodes were collected using a Baermann funnel with $100 \mathrm{~mL}$ sterile water under aseptic conditions and stored at $4{ }^{\circ} \mathrm{C}$ [21]. A total of $1 \mu \mathrm{L}$ of the obtained nematode solution was used as the template for $50 \mu \mathrm{L}$ PCR amplification reaction. The S. maltophilia suspension was used as a control. Fragments of $16 \mathrm{~S}$ rDNA gene were amplified using $2 \times$ TSINGKE Master Mix according to the manufacturer's instructions (Beijing TsingKe Biotech Co., Ltd., Nanjing, China) with bacterial universal primer pairs of 27F (5'-AGAGTTTGATCCTGGCTCAG-3') and 1492R (5'-TACCTTGTTACGACTT-3'). PCR products were subjected to electrophoresis in $1 \%$ agarose gel to verify the size of target fragments and afterwards sent to Beijing TsingKe Biotech Co., Ltd. (Nanjing, China) for sequencing. The determined sequences were then compared with the $16 \mathrm{~S}$ rDNA of S. maltophilia (NSPmBx03) using DNAMAN software (https://www.lynnon.com/index.html). Consistent sequences indicated that the nematode only carried S. maltophilia and the PWNs carrying S. maltophilia $\left(\mathrm{Bx} \_b\right)$ had been obtained.

\subsection{Preparation of Aseptic P. massoniana Seedlings}

Mature seeds of $P$. massoniana were washed with tap water for $1 \mathrm{~h}$, soaked in $30 \% \mathrm{H}_{2} \mathrm{O}_{2}$ for $30 \mathrm{~min}$ and rinsed with $3 \mathrm{~L}$ sterile water. The aseptic seeds were placed on water agar with $0.1 \mathrm{~g} / \mathrm{L}$ agar at $25^{\circ} \mathrm{C}$. The germination process was monitored frequently, and uncontaminated germinated seedlings were transferred to aseptic culture bottles containing a paper cup with perlite and 30-50 mL Gresshoff and Doy (GD) liquid medium without any growth regulators at the bottom [24,25]. The aseptic P. massoniana seedlings were cultured for 4 months under controlled conditions (temperature $25^{\circ} \mathrm{C}$, $16 \mathrm{~h}$ of light at $2000 \mathrm{~lx}$ ). Clear GD medium was an indication that $P$. massoniana seedlings were aseptic.

\subsection{B. xylophilus Inoculation}

Under aseptic conditions, the shoot tips of four-month-old P. massoniana aseptic seedlings were cut away with sterilized scissors, and a piece of aseptic absorbent cotton wool was placed on the wound. A suspension of 200 nematodes was pipetted into the cotton wool. The aseptic pines were inoculated with PWNs Bx_a and Bx_b, respectively. For each treatment 24 seedlings were used, and as control (CK) plants were inoculated with S. maltophilia alone. Pines were cultured at $25{ }^{\circ} \mathrm{C}$, with $2000 \mathrm{~lx}$ and $16 \mathrm{~h}$ of light per day. The disease incidence in the P. massoniana was observed and recorded regularly. The infection rate and disease severity index (DSI) of P. massoniana were calculated according to Yu et al. [26]. The incidence level of PWD was divided levels 0 to 4: $0=$ all needles were green; 
$1=0-25 \%$ of needles turned yellow; $2=25-50 \%$ of needles turned yellow; $3=50-75 \%$ of needles turned yellow; and $4=75-100 \%$ of needles turned yellow. The calculation formula was as follows:

$$
\begin{gathered}
\text { Infection rate }(\%)=\frac{\sum \text { Number of infected plants with symptoms }}{\text { Total number of plants }} \times 100 \\
\text { Disease severity index }(\text { DSI })=\frac{\sum \text { Number of diseased plants } \times \text { symptom stage }}{\text { Total number of plants } \times \text { highest symptom stage }} \times 100
\end{gathered}
$$

Seven days post inoculation (dpi), the PWNs of each treatment were separated under aseptic conditions by the Berman funnel method, and aseptic PWNs (PmBx_a) and PWNs with S. maltophilia $\left(\mathrm{PmBx} \_\mathrm{b}\right)$ were obtained and their reproduction were counted. The ratio of the final population to the initial reproduction of nematodes were presented as means \pm standard deviation (Mean \pm S.D.). All parameters were calculated using Microsoft Excel and GraphPad Prism 5 (GraphPad Software, San Diego, CA, USA). The statistical significance was determined using SPSS Statistics 24.0 software (IBM China Company Ltd., Beijing, China). A Student's t-test was used to compare two samples. The level of significance was $p<0.05$. A small amount of nematode solution from each treatment was taken for the sterility test and morphological observation. The rest of the nematodes were rinsed with sterile water 3-5 times and centrifuged, and the supernatant was removed, frozen in liquid nitrogen, and stored in a refrigerator at $-80^{\circ} \mathrm{C}$ for subsequent analyses.

\subsection{RNA Extraction and Sequencing}

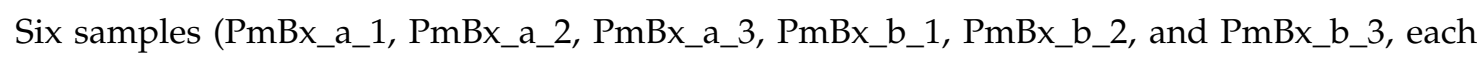
treatment had three replicates) were used for RNA sequencing. Total RNA was extracted from the nematodes with TRIzol reagent (Invitrogen, Waltham, MA, USA) according to the manufacturer's protocol. The RNA quality was assessed using an Agilent 2100 Bioanalyzer (Agilent Technologies, Santa Clara, CA, USA). Total RNA with a concentration higher than $20.0 \mathrm{ng} / \mu \mathrm{L}$, a total mass higher than $1.0 \mu \mathrm{g}$, an RNA integrity number (RIN) over 7.0, and 28S/18S no less than 1.0 was used for library preparation. RNA-Seq library construction and paired-end sequencing on an Illumina HiSeq X-Ten was completed at Beijing Genomics Institute (Shenzhen, China). The RNA-Seq experiments have three technical replicates. The data have been submitted to NCBI, and the accession number is SRR11474049- SRR11474054.

\subsection{RNA-Seq Analysis}

The RNA-Seq data were cleaned using SOAPnuke (https://github.com/BGI-flexlab/SOAPnuke) to remove adaptors, reads with unknown bases $(\mathrm{N})>5 \%$, and low-quality sequences (quality score $(\mathrm{Q} 20)<20)$. After filtering, high-quality reads were then mapped to the B. xylophilus genome (BioProject PRJEA64437) [27] using Hierarchical Indexing for Spliced Alignment of Transcripts (HISAT) [28]. StringTie was used to do transcript reconstruction of each sample [29]. Cuffmerge was used to integrate the reconstruction information of all samples, and then Cuffcompare was used to compare the integrated transcript with the reference annotation information [30]. Transcripts with class code types of " $\mathrm{u}$ ", " $\mathrm{i}$ ", " $\mathrm{o}$ ", and " $\mathrm{j}$ " were selected and defined as the new transcripts. The protein coding potential of the new transcripts was predicted by CPC [31], and the new transcripts with predicted protein coding potential were added to the reference gene sequences to obtain a complete reference sequence information, which would be analyzed in the future. Clean reads were compared to the reference sequence to calculate the gene alignment rate by Bowtie 2 [32]. The expression levels of genes and transcripts were calculated using RSEM (RNA-Seq by Expectation Maximization) [33]. Genes with an absolute value of $\log _{2}$ fold change $\geq 1$ and an adjusted $p$-value (padj) $\leq 0.05$ were considered to be differentially expressed genes (DEGs) [34]. The reference genome of B. xylophilus was used as the background to determine significantly enriched gene ontology (GO) terms and Kyoto Encyclopedia of Genes and Genomes (KEGG) pathways enriched within DEGs. A false discovery rate (FDR) $\leq 0.01$ was 
used to indicate statistically significant enrichment. DIAMOND [35] software was used to compare the DEGs to the STRING [36] database, resulting in the identification of DEG-encoded protein interactions based on their homology with known proteins. The whole interaction relationship was visualized by Cytoscape software [37].

\section{8. qPCR Validation}

The real-time quantitative polymerase chain reaction (qPCR) was carried out to confirm the expression of 9 randomly selected DEGs (significantly different expression) using the same RNA samples that were used in sequencing. First-Strand cDNA was synthesized using HiScript ${ }^{\circledR}$ II $Q$ RT SuperMix for qPCR (+gDNA wiper) (Vazyme, Nanjing, China) following the product manual. The gene-specific primers for q-PCR were designed by Primer Premier 5 (Table S1). The housekeeping actin gene of B. xylophilus was utilized as a reference gene. The cDNA products were amplified by SYBR Green Master Mix (Vazyme, Nanjing, China) on the ABI PRISM 7500 Real-Time PCR System (Applied Biosystems, Foster City, CA, USA). Each q-PCR was conducted in triplicate, and then relative gene expression levels were analyzed by the $2^{-\Delta \Delta \mathrm{Ct}}$ method.

\section{Results}

\subsection{Effect of S. maltophilia on the Virulence of B. xylophilus}

At 3 dpi, thirteen P. massoniana seedlings inoculated with aseptic PWNs (Bx_a) began to lose water and turn brown; the infection rate was $54.17 \%$, and the disease severity index (DSI) was 13.54 . Twenty-one pine seedlings inoculated with the nematode with S. maltophilia (Bx_b) showed infection; the infection rate was $87.50 \%$, and the DSI was 21.88. At $5 \mathrm{dpi}, 23$ pine seedlings inoculated with Bx_a showed symptoms of PWD; the infection rate was 95.83\%, and the DSI was 23.96. All of the pines inoculated with Bx_b had symptoms of PWD; the infection rate was 100\%, and the DSI was 25. At 7 dpi, all the seedlings of P. massoniana inoculated with Bx_a were infected, the infection rate was $100 \%$, the DSI was 37.50; the infection rate of P. massoniana inoculated with Bx_b was 100\%, and the DSI was 38.54. The P. massoniana inoculated with S. maltophilia alone did not show any symptoms (Figure 1 , Table 1). The seedlings inoculated with Bx_b showed earlier and more visible symptoms than those inoculated with Bx_a. At this time, the number of PmBx_a was 6.74 times of the initial inoculation (Bx_a), and the number of PmBx_b was 7.91 times of the initial inoculation (Bx_b), but the difference between the two treatments was not significant (Figure 2). It is suggested that S. maltophilia could enhance the virulence of PWNs.

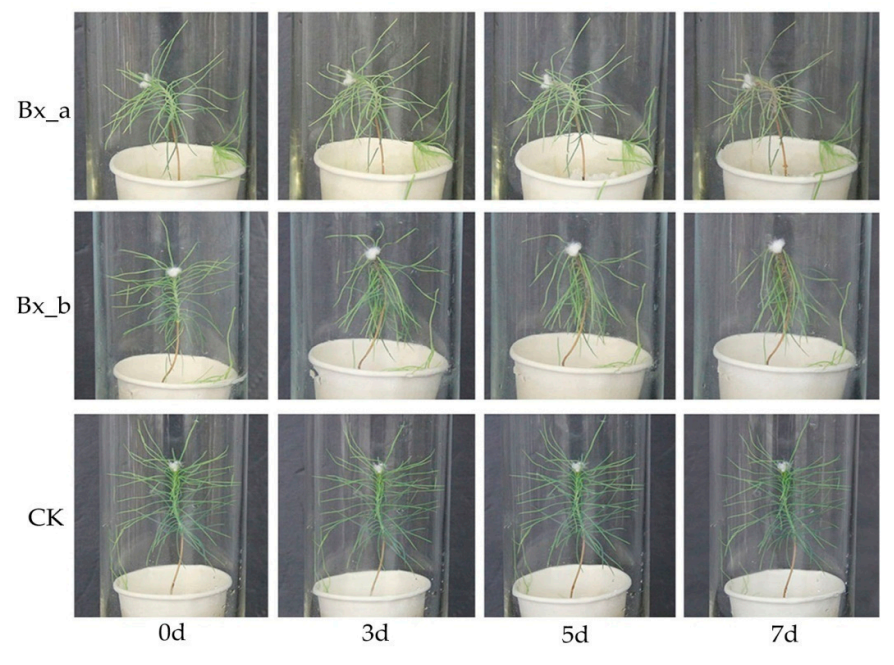

Figure 1. Disease phenotype of pine seedlings inoculated with aseptic B. xylophilus (Bx_a), B. xylophilus with S. maltophilia (Bx_b), or S. maltophilia alone (CK), at $0,3,5$, and 7 days post inoculation (dpi), respectively. 
Table 1. The degree of pine wilt disease after P. massoniana seedlings were inoculated with aseptic B. xylophilus (Bx_a), B. xylophilus with S. maltophilia (Bx_b), or S. maltophilia alone (CK), at 3, 5, and 7 days post inoculation (dpi), respectively.

\begin{tabular}{ccccccc}
\hline \multirow{2}{*}{ Treatment } & \multicolumn{3}{c}{ Infection Rates (\%) } & \multicolumn{3}{c}{ Disease Severity Index (DSI) } \\
\cline { 2 - 7 } & $\mathbf{3} \mathbf{d p i}$ & $\mathbf{5} \mathbf{d p i}$ & $\mathbf{7 ~ d p i}$ & $\mathbf{3 ~ d p i}$ & $\mathbf{5} \mathbf{d p i}$ & $\mathbf{7 ~ d p i}$ \\
\hline Bx_a & 54.17 & 95.83 & 100 & 13.54 & 23.96 & 37.50 \\
Bx_b & 87.50 & 100 & 100 & 21.88 & 25 & 38.54 \\
CK & 0 & 0 & 0 & 0 & 0 & 0 \\
\hline
\end{tabular}

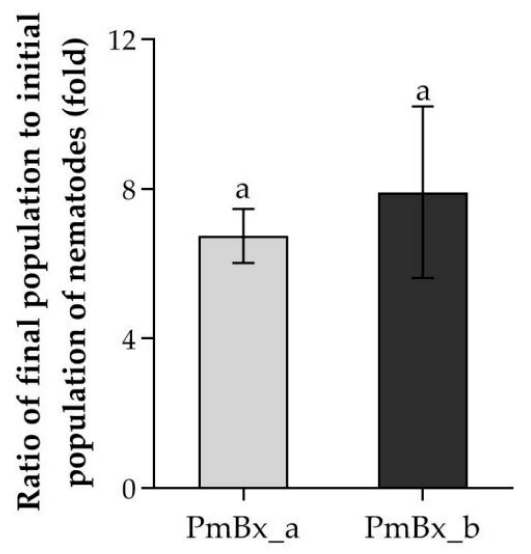

Figure 2. Population of B. xylophilus at 7 days post inoculation (dpi). Aseptic B. xylophilus (PmBx_a), B. xylophilus with S. maltophilia (PmBx_b). The bars indicate S.D., and two samples with a common letter are not significantly different $(p>0.05)$ according to the Student's $t$ test.

\subsection{Transcriptome Sequencing and Differentially Expressed Genes}

RNA sequencing of six independent B. xylophilus samples (three PmBx_a and three PmBx_b) was performed on an Illumina HiSeq platform to characterize the transcriptome and measure the differential expression of genes, generating 54.03 to $58.30 \mathrm{Mb}$ of raw reads per sample. After quality filtering, $44.55(76.43 \%)$ to $45.31(83.78 \%) \mathrm{Mb}$ of clean reads were obtained, with an average of $6.75 \mathrm{~Gb}$ bases. Subsequently, the clean reads were mapped to the B. xylophilus reference genome. Approximately $77.12-79.77 \%$ of reads matched the sequences in the genome, and $62.13-66.25 \%$ of the reads were uniquely mapped. When the clean reads mapped to reference genes, the total mapping ratio was $67.39-69.71 \%$, and the unique ratio was $58.62-60.26 \%$ (Table 2). A total of 10,187 new transcripts were detected in the transcripts of the two treatments, of which 8359 were predicted to have coding potential, 7901 were predicted to be new transcripts of known genes with protein coding potential, 458 were new transcripts of new genes with protein coding potential, and 1828 were non-coding transcripts (Table 3). Expression levels of genes and transcripts were calculated using RSEM (RNA-Seq by Expectation Maximization). There were 4240 DEGs (absolute value of $\log _{2}$ fold change $\geq 1$ and adjusted $p$-value $\leq 0.05$ ) between the bacteria-treated and bacteria-free B. xylophilus, including 2763 downregulated and 1477 upregulated DEGs (Figure 3). The number of no-DEGs (absolute value of $\log _{2}$ fold change $<1$ or adjusted $p$-value $>0.05$ ) was 11,942 .

Table 2. Statistical data for RNA sequencing.

\begin{tabular}{ccccccc}
\hline Sample & $\begin{array}{c}\text { Total Raw } \\
\text { Reads (Mb) }\end{array}$ & $\begin{array}{c}\text { Total Clean } \\
\text { Reads (Mb) }\end{array}$ & $\begin{array}{c}\text { Total Clean } \\
\text { Bases (Gb) }\end{array}$ & $\begin{array}{c}\text { Clean Reads } \\
\text { Ratio (\%) }\end{array}$ & $\begin{array}{c}\text { Total Mapping } \\
\text { Ratio (\%) }\end{array}$ & $\begin{array}{c}\text { Uniquely Mapping } \\
\text { Ratio (\%) }\end{array}$ \\
\hline PmBx_a_1 & 58.30 & 44.55 & 6.68 & 76.43 & $77.12 \%$ & $62.13 \%$ \\
PmBx_a_2 & 56.68 & 45.31 & 6.80 & 79.95 & $78.46 \%$ & $62.67 \%$ \\
PmBx_a_3 & 55.06 & 44.57 & 6.69 & 80.96 & $79.77 \%$ & $63.87 \%$ \\
PmBx_b_1 & 54.04 & 45.27 & 6.79 & 83.78 & $78.97 \%$ & $65.49 \%$ \\
PmBx_b_2 & 54.03 & 45.2 & 6.78 & 83.66 & $79.72 \%$ & $66.25 \%$ \\
PmBx_b_3 & 54.04 & 45.13 & 6.77 & 83.53 & $79.51 \%$ & $66.12 \%$ \\
\hline
\end{tabular}


Table 3. New transcripts in the transcriptomes of aseptic B. xylophilus and B. xylophilus with S. maltophilia after inoculation.

\begin{tabular}{ccccc}
\hline Total Novel Transcript & Coding Transcript & Noncoding Transcript & Novel Isoform & Novel Gene \\
\hline 10,187 & 8359 & 1828 & 7901 & 458 \\
\hline
\end{tabular}

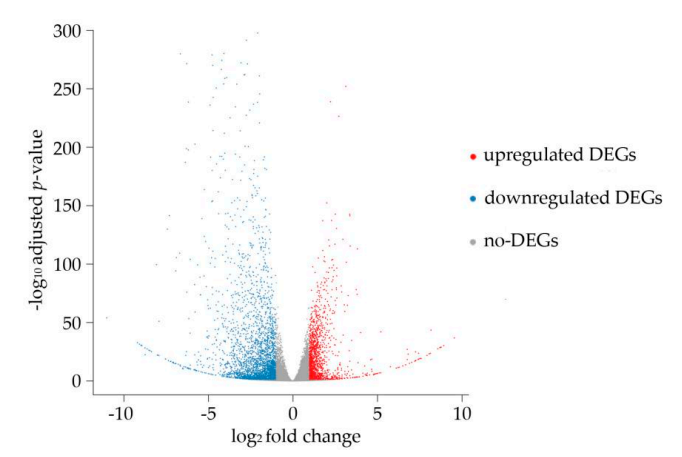

Figure 3. Volcano-Plot of differentially expressed genes (DEGs) of pine wood nematodes in aseptic condition and with $S$. maltophilia. The number of upregulated DEGs $\left(\log _{2}\right.$ fold change $\geq 1$, adjusted $p$-value $\leq 0.05)$ is 1477 , the number of downregulated DEGs $\left(\log _{2}\right.$ fold change $\leq-1$, adjusted $p$-value $\leq 0.05$ ) is 2763 , the number of no-DEGs (absolute value of $\log _{2}$ fold change $<1$ or adjusted $p$-value $>0.05)$ is 11,942 .

\section{3. qPCR Verification of Differentially Expressed Genes}

Nine genes (7 upregulated genes and 2 downregulated genes) with high expression differences were randomly selected from PmBx_a and PmBx_b transcripts for qPCR verification. The expression trends of gene transcripts were consistent with the results of qPCR verification, indicating that the sequencing data were reliable (Figure 4).
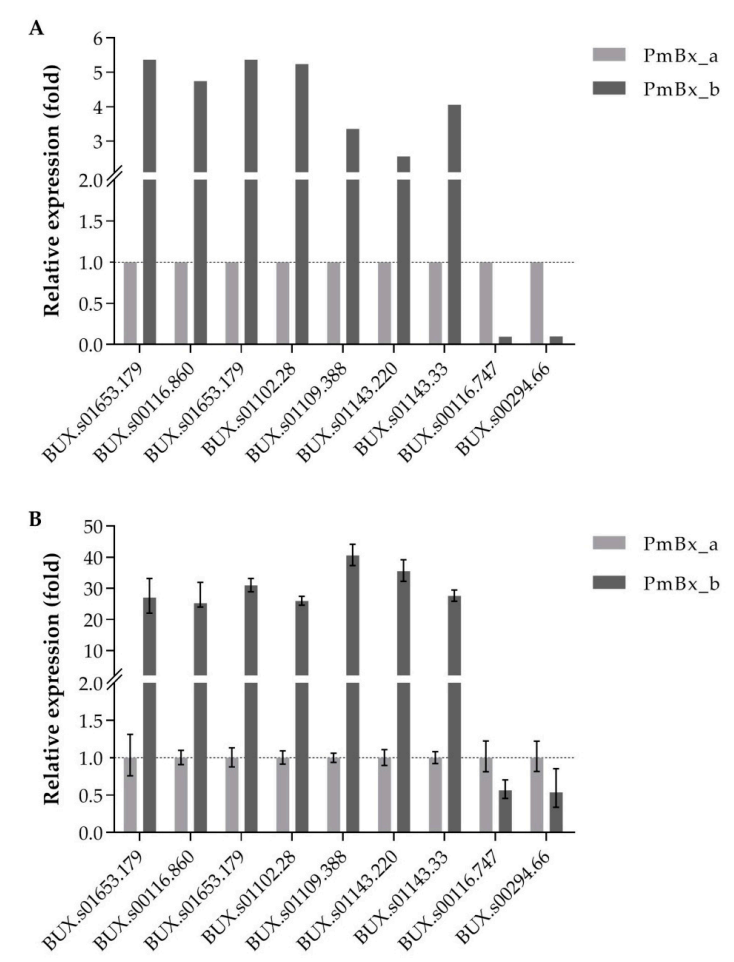

Figure 4. Relative expression of differentially expressed genes of B. xylophilus in aseptic condition (PmBx_a) or with S. maltophilia (PmBx_b). Relative expression of differentially expressed genes by sequencing (A) and the real-time quantitative polymerase chain reaction (qPCR) (B), the bars indicate S.D. 


\subsection{Characterization of Differentially Expressed Transcripts}

All the transcripts were further functionally characterized into three GO categories: biological process, cellular component, and molecular function. Among the set of 4240 DEGs, 356 genes were associated with at least one GO term, and a total of 50 different $\mathrm{GO}$ terms were found. Twenty-four GO terms were involved in biological processes, $16 \mathrm{GO}$ terms were associated with cellular components, and 10 GO terms had various molecular functions (Figure 5). Among the biological process terms, the cellular process, single-organism process, and metabolic process terms were the three terms containing the greatest number of DEGs. In the cellular component category, the top three GO terms were cell, cell part, and membrane, and for the molecular function category, catalytic activity, binding, and transporter activity were the top three terms (Figure 5).

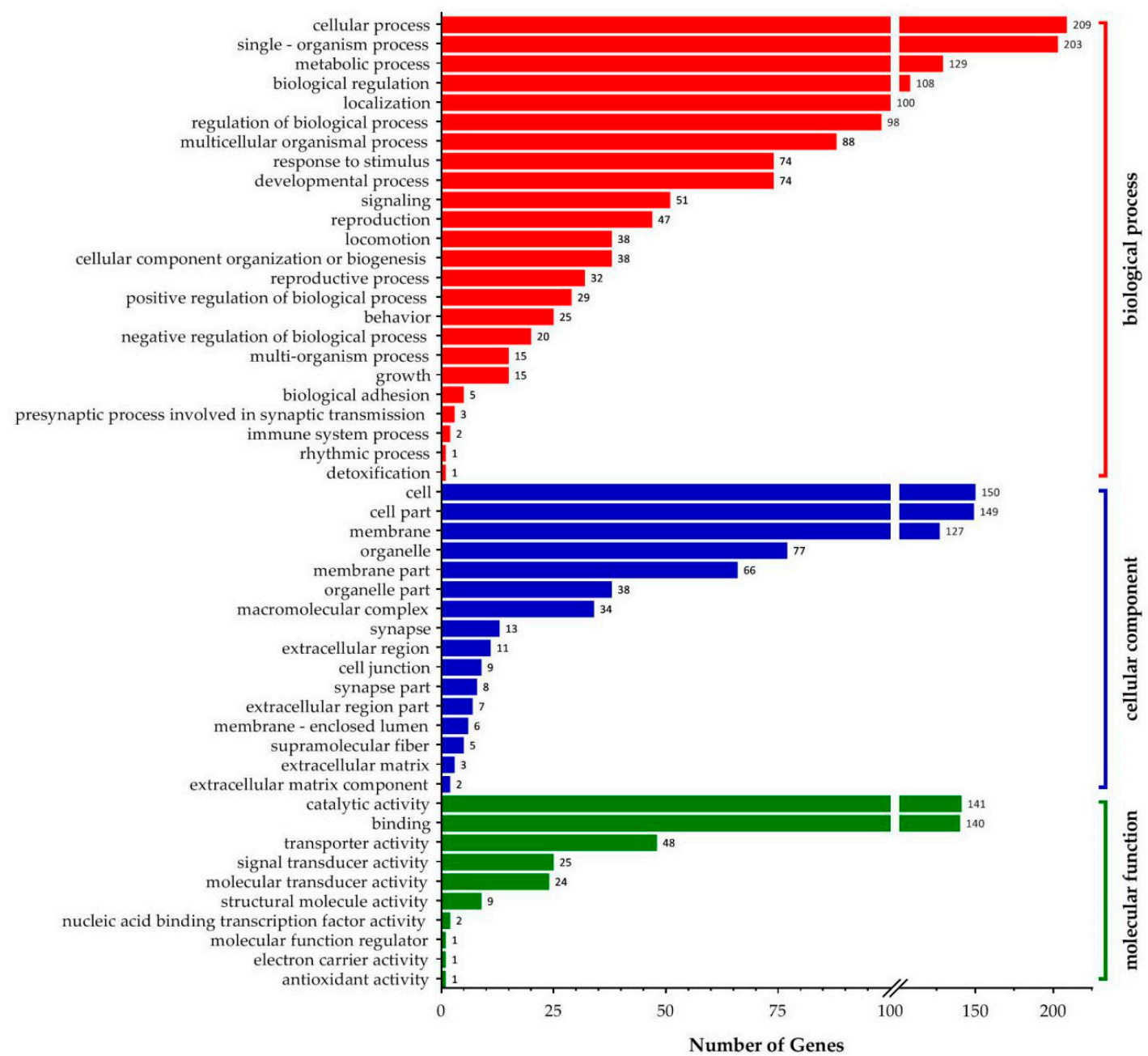

Figure 5. GO categories of differentially expressed genes of B. xylophilus in aseptic condition and with S. maltophilia.

The putative functions of DEGs were also analyzed with KEGG classification. The 871 DEGs could be mapped to 301 different pathways that might be affected by S. maltophilia. KEGG Orthology $(\mathrm{KO})$ analysis showed that most DEGs were assigned to human diseases, metabolism, and organismal systems. In the human diseases class, "cancers: overview", "endocrine and metabolic diseases", and "infectious diseases: bacterial" had many DEGs. "Global and overview maps", "lipid metabolism", "carbohydrate metabolism", and "amino acid metabolism" were the dominant terms in the metabolism class. Few transcripts were assigned to "xenobiotic biodegradation and metabolism" (23 transcripts) and "metabolism of terpenoids and polyketides" (6 transcripts) (Figure 6). This result showed that 
S. maltophilia mainly affected the growth and development of nematodes. In the organismal systems category, "immune system", "endocrine system", and "digestive system" had more transcripts. The top five enriched groups among the KEGG categories included signal transduction, cancers: overview, global and overview maps, cellular community-eukaryotes, and immune system.

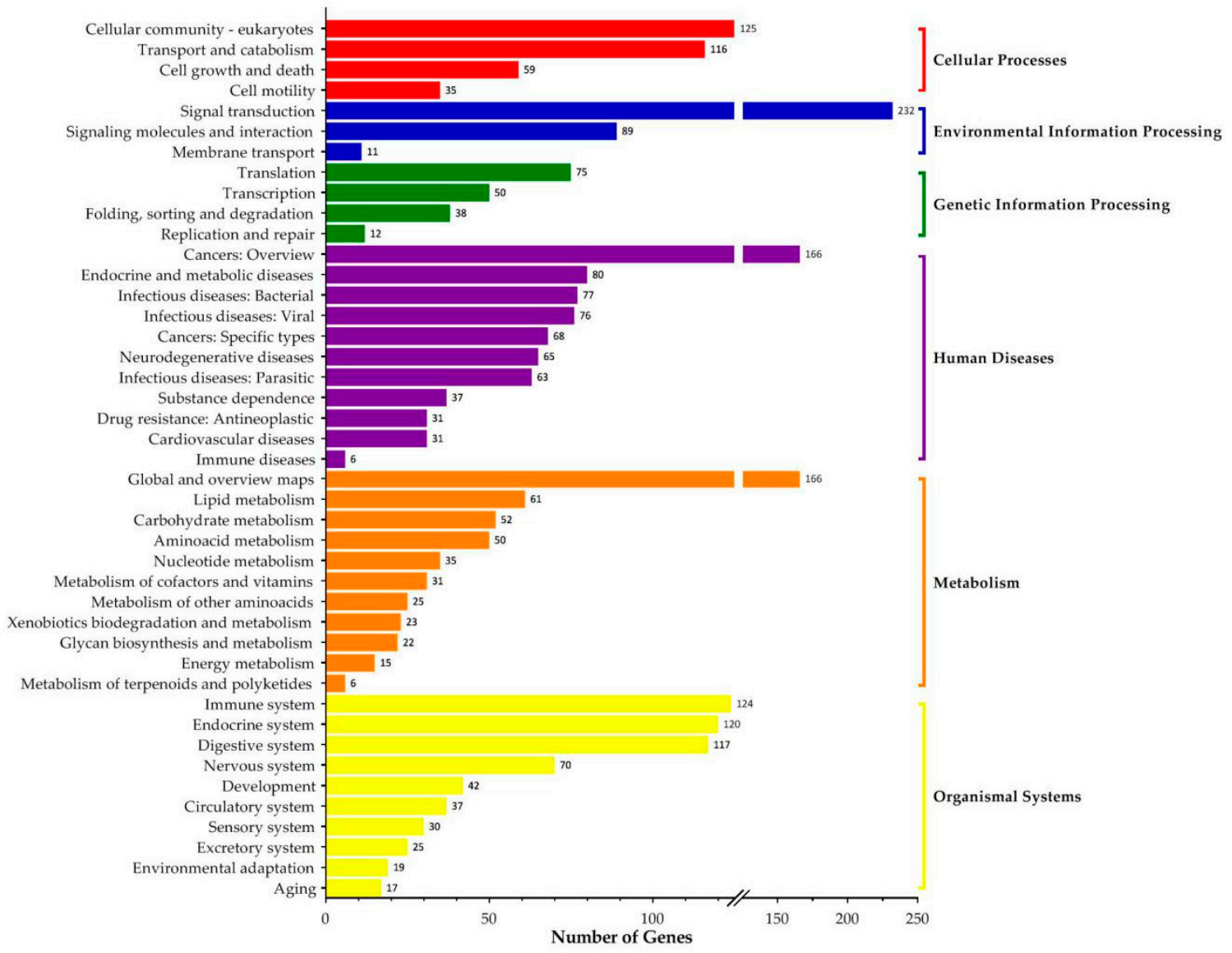

Figure 6. Kyoto Encyclopedia of Genes and Genomes (KEGG) classifications of differentially expressed genes of B. xylophilus in aseptic condition and with S. maltophilia.

A list of the top 30 pathways and number of transcripts mapped to those pathways are shown in Figure 7. The most highly active pathway was cancer (ko05200), with 72 active transcripts, followed by protein digestion and absorption (ko04974, 59 transcripts). A number of signaling pathways that are known to be involved in development and diverse functions were active in PmBx_a, such as the wnt signaling pathway (ko04310), rap1 signaling pathway (ko04015), PI3K-Akt signaling pathway (ko04151), cAMP signaling pathway (ko04024), cGMP-PKG signaling pathway (ko04022), ECM-receptor interaction, MAPK signaling pathway (ko04010), and calcium signaling pathway (ko04020). Thus, it can be concluded that S. maltophilia affects the immune system of B. xylophilus. 


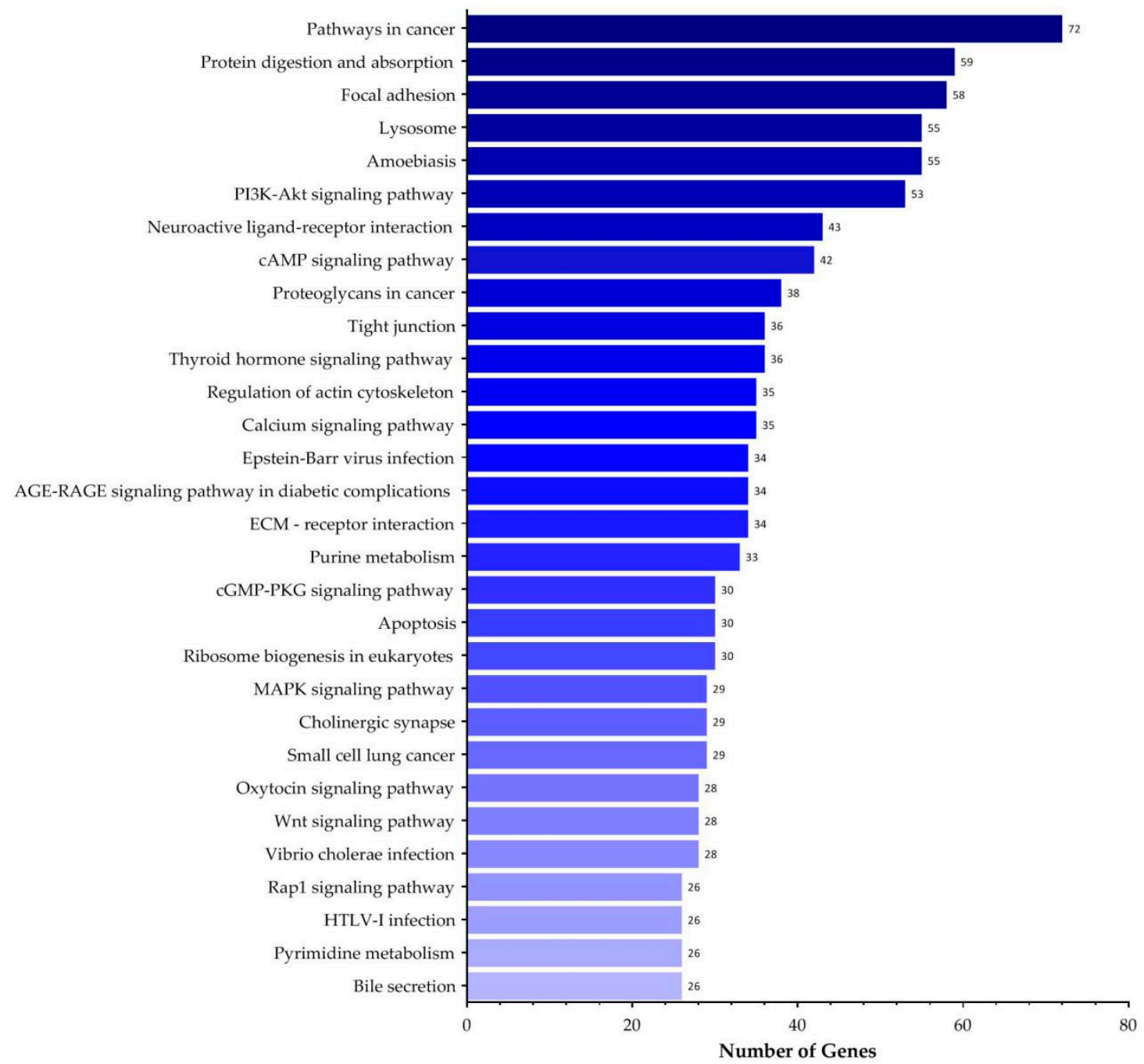

Figure 7. The top 30 pathways of differentially expressed genes of B. xylophilus between aseptic condition and with S. maltophilia.

\subsection{Nematode Response Gene Network}

The 4240 DEGs were compared to the STRING database, 2196 of which could be mapped to 2007 protein clusters (Table S1). Cytoscape software was used to analyze and visualize these DEGs, resulting in many interaction networks (Figure 8). The genes central to a highly connected network have been shown to be more likely to have essential functions. Thus, we hypothesized that genes central to the identified network would be fundamental to the B. xylophilus response to the host pine seedlings. Table 4 lists the top 20 central genes (hubs) in the network and the number of genes connected to the listed gene. There were 238 genes encoding proteins interacting with the gene BUX.s01653.391 (polyubiquitin). Second, genes BUX.s00397.130 and BUX.s00397.132 encoded the leucine-rich repeat serine/threonine protein kinase and interacted with 116 different genes. Other genes, including BUX.s01281.46 (Glyceraldehyde-3-phosphate dehydrogenase), BUX.s00138.1 (DNA topoisomerase 2), BUX.s00422.590 (1-phosphatidylinositol 3-phosphate 5-kinase), BUX.s00813.122 (Acetyl-CoA carboxylase), five heat shock protein genes BUX.s00116.357, BUX.s00961.158, BUX.s01281.74, BUX.s00422.612, BUX.s01644.6, and two myosin genes BUX.s01281.438 and BUX.s00083.40, also interacted with many different DEGs (Table 4). 

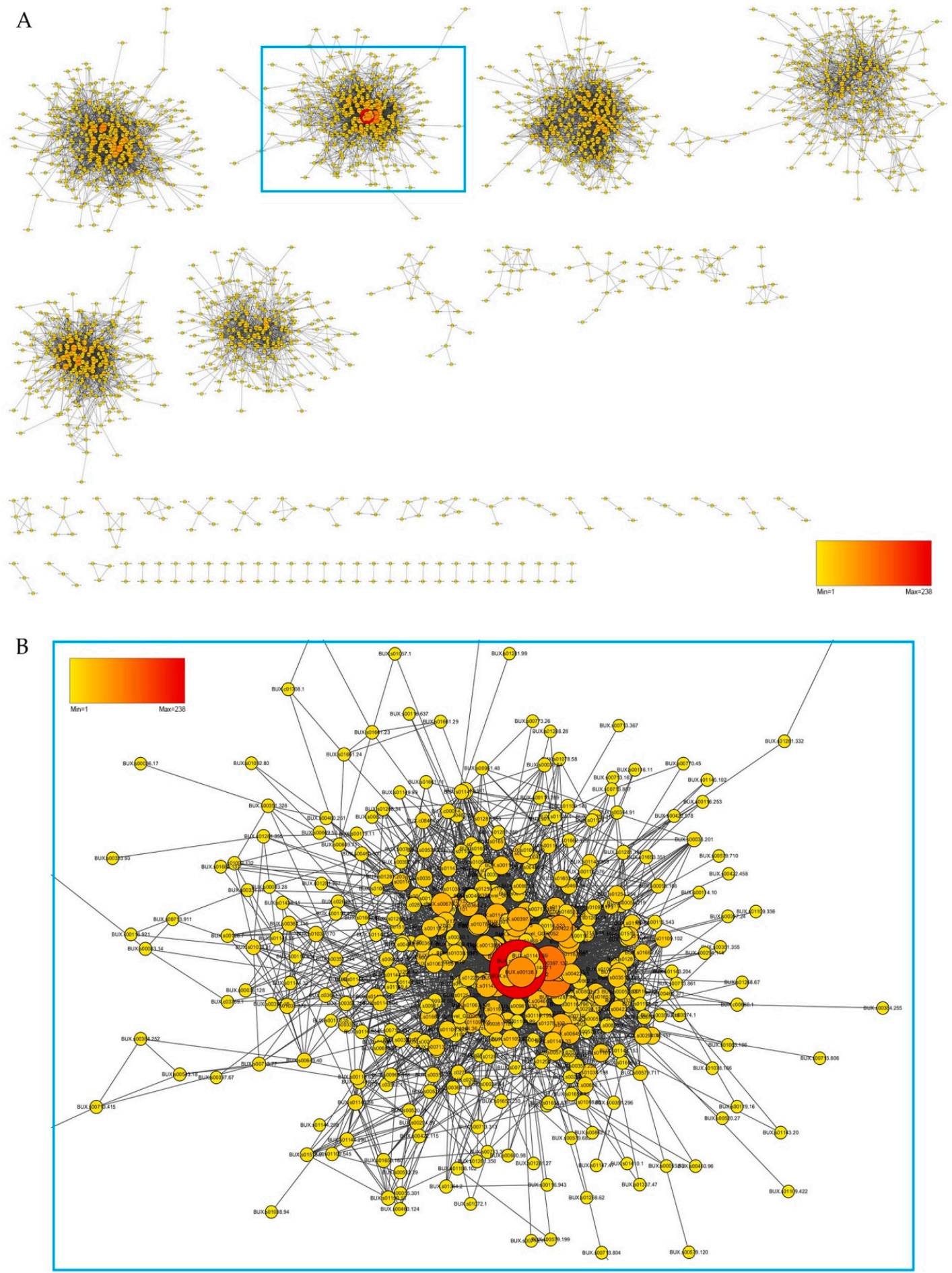

Figure 8. Interactions of proteins encoded by differentially expressed genes of B. xylophilus between aseptic condition and with S. maltophilia. Protein interactions of all differentially expressed genes (A); enlarged view of protein interactions $(\mathbf{B})$. The larger the circle and the redder the color, the more proteins interacted with the protein, and the smaller and yellow the fewer interactions. 
Table 4. Genes that interacted with many differentially expressed genes of B. xylophilus between aseptic condition and with $S$. maltophilia.

\begin{tabular}{ccc}
\hline Gene ID & N & Predicted Protein \\
\hline BUX.s01653.391 & 238 & Polyubiquitin \\
BUX.s00397.130 & 116 & Leucine-rich repeat serine/threonine-protein kinase \\
BUX.s00397.132 & 116 & Leucine-rich repeat serine threonine-protein kinase 1 \\
BUX.s01281.46 & 99 & Glyceraldehyde-3-phosphate dehydrogenase \\
BUX.s00138.1 & 92 & DNA topoisomerase 2 \\
BUX.s00422.590 & 87 & 1-phosphatidylinositol 3-phosphate 5-kinase \\
BUX.c03835.1 & 86 & NA \\
BUX.s00813.122 & 86 & Acetyl-CoA carboxylase \\
BUX.s01109.1 & 84 & DNA-directed RNA polymerase I subunit RPA1 \\
BUX.s01254.380 & 80 & Neur_chan_LBD domain-containing protein \\
BUX.s01198.7 & 75 & Glutamyl(E) Amino-acyl tRNA Synthetase \\
BUX.s00364.24 & 74 & cell differentiation family, Rcd1 \\
BUX.s00116.357 & 73 & Heat shock protein 70 \\
BUX.s00961.158 & 73 & Heat shock protein 70 \\
BUX.s01281.74 & 73 & Heat shock protein 70 \\
BUX.s00422.612 & 72 & Meat shock protein 75 kDa, mitochondrial \\
BUX.s01281.437 & 72 & Myosin \\
BUX.s01281.438 & 72 & Nyosin \\
BUX.s00083.40 & 71 & Neat Shock Protein 110 \\
BUX.s01644.6 & 70 & Hech
\end{tabular}

Note: number of DEGs interacting with this gene $(\mathrm{N})$.

\subsection{Differential Expression of Virulence Genes in B. xylophilus}

According to the annotation information, a series of virulence genes were found to be differentially expressed in PmBx_a and PmBx_b (Table 5). Four genes were related to cell wall hydrolysis (including the pectinase gene and cellulase gene), one of which was upregulated, and the other three were downregulated. Thirty-Six detoxification-related genes (including the cytochrome P450 gene, toxic anaphylactic protein gene, glutathione S-transferase gene, $\mathrm{ABC}$ transporter gene, retinol dehydrogenase gene, carboxylesterase gene, etc.) were differentially expressed, including ten upregulated and twenty-six downregulated genes. Ten cathepsin L-cysteine protease genes were differentially expressed, including five upregulated and five downregulated genes. In addition, an effector gene (BxSapB2) of PWN was upregulated.

Table 5. Differentially expressed genes associated with virulence of B. xylophilus in P. massoniana inoculated with B. xylophilus alone (PmBx_a), or B. xylophilus with S. maltophilia (PmBx_b).

\begin{tabular}{ccc}
\hline Gene ID & $\log _{\mathbf{2}}$ Fold Change $\left(\mathbf{P m B x \_ b / P m B x \_ a )}\right.$ & Up/Down-Regulation \\
\hline & Pectate lyase & \\
BUX.s01259.20 & -4.074762625 & Down \\
BUX.s01259.23 & -4.182790139 & Down \\
BUX.s01259.21 & -4.510202593 & Down \\
& Cellulase & \\
BUX.s01066.64 & 4.618501404 & $\mathrm{Up}$ \\
BUX.s01288.37 & -4.09111163 & Down \\
BUX.c09083.1 & Glutathiones-transferase & Up \\
BUX.s01513.258 & 1.669839508 & Down \\
BGI_novel_G000432 & -1.139784616 & Down \\
\hline
\end{tabular}


Table 5. Cont.

\begin{tabular}{|c|c|c|}
\hline Gene ID & $\log _{2}$ Fold Change (PmBx_b/PmBx_a) & Up/Down-Regulation \\
\hline \multicolumn{3}{|c|}{ Cytochrome P450, CYP } \\
\hline BUX.s01661.6 & 1.557847634 & Up \\
\hline BUX.s01144.121 & -1.000995452 & Down \\
\hline BUX.s00116.502 & -1.063038854 & Down \\
\hline BUX.s00116.734 & -1.208684047 & Down \\
\hline BUX.s00298.246 & -1.442207328 & Down \\
\hline BUX.s00116.879 & -1.480500102 & Down \\
\hline BUX.s00460.194 & -1.575995247 & Down \\
\hline BUX.s01038.7 & -1.821369766 & Down \\
\hline \multicolumn{3}{|c|}{$\mathrm{ABC}$ transporter } \\
\hline BUX.s01254.42 & -2.29841047 & Down \\
\hline \multicolumn{3}{|c|}{ Venom allergen-like protein VAP1 } \\
\hline BUX.s00579.80 & 1.052640318 & Up \\
\hline BGI_novel_G000391 & -1.028089184 & Down \\
\hline BUX.s00116.787 & -1.218428765 & Down \\
\hline BUX.s01147.77 & -1.646314785 & Down \\
\hline \multicolumn{3}{|c|}{ Retinol dehydrogenase } \\
\hline BUX.s00579.178 & 1.316943271 & Up \\
\hline BUX.s00974.41 & -1.492689553 & Down \\
\hline \multicolumn{3}{|c|}{ Carboxylesterase } \\
\hline BUX.s01226.30 & 1.181734176 & Up \\
\hline BUX.s00713.1002 & 1.17453585 & Up \\
\hline BUX.s00579.243 & 1.135072687 & $\mathrm{Up}$ \\
\hline BUX.s01145.139 & -1.065237837 & Down \\
\hline BUX.s00364.64 & -1.137734342 & Down \\
\hline BUX.s00110.90 & -1.143247115 & Down \\
\hline BUX.s01147.205 & -1.666055127 & Down \\
\hline BUX.s00983.9 & -2.183381707 & Down \\
\hline BUX.s00110.48 & -2.753293911 & Down \\
\hline \multicolumn{3}{|c|}{ UDP-glucuronosyl transferase, UGT } \\
\hline BUX.s00460.320 & 1.796726932 & \\
\hline BUX.s00139.166 & 1.068078732 & Up \\
\hline BUX.s00351.21 & 1.057762705 & Up \\
\hline BUX.s00649.18 & -1.186354129 & Down \\
\hline BUX.s01438.42 & -1.193137892 & Down \\
\hline BUX.s00116.87 & -1.341914185 & Down \\
\hline BUX.s01092.146 & -1.490960439 & Down \\
\hline BUX.s01109.36 & -1.580165084 & Down \\
\hline BUX.s00460.69 & -2.061031941 & Down \\
\hline \multicolumn{3}{|c|}{ BxSapB2 } \\
\hline BUX.s01063.105 & 1.016870986 & Up \\
\hline \multicolumn{3}{|c|}{ Cathepsin L-like cysteine protease } \\
\hline BUX.s01656.41 & 6.784683942 & Up \\
\hline BGI_novel_G000167 & 3.834868069 & Up \\
\hline BUX.s00813.51 & 3.395018418 & $\mathrm{Up}$ \\
\hline BUX.s00813.52 & 3.153518163 & Up \\
\hline BUX.s00116.604 & 2.076060588 & Up \\
\hline BUX.s00497.2 & -1.048755246 & Down \\
\hline BUX.s01288.15 & -1.301409481 & Down \\
\hline BGI_novel_G000040 & -1.423476978 & Down \\
\hline BUX.s00713.1009 & -2.220301991 & Down \\
\hline BUX.s00713.1011 & -2.901975575 & Down \\
\hline
\end{tabular}

\section{Discussion}

S. maltophilia is a kind of Gram-negative bacteria that is widely distributed in nature [38]. This species is also widely found in different PWN strains, and its relative abundance is high $[15,17,19]$. 
He et al. found that wild-type three-year-old P. massoniana inoculated with nematodes containing S. maltophilia wilted faster than those inoculated with aseptic pine wood nematodes [20]. Since wild pine carries a variety of microorganisms, four-month-old aseptic P. massoniana seedlings were used for the inoculation experiment in our study. The results provided more direct evidence that $S$. maltophilia can enhance the reproduction and virulence of B. xylophilus.

To explore the mechanism of the effect of $S$. maltophilia on PWNs in PWD, transcriptome sequencing of aseptic PWNs and those carrying S. maltophilia after inoculation was carried out. The results showed that 4240 genes were differentially expressed between the two treatments, including 1147 upregulated genes and 2763 downregulated genes. Compared with the transcriptomes of aseptic PWNs and the PWNs carrying S. maltophilia cultured on B. cinerea, which have 891 significantly DEGs, including 61 upregulated genes and 830 downregulated genes [21], the number of DEGs in the comparative transcriptome of aseptic PWNs and PWNs with S. maltophilia in pines was much higher. This suggests that different habitats could affect the gene expression of PWN, which is also reflected in the studies of Qiu et al. [39] and Tsai et al. [40].

Furthermore, the potential functions of DEGs in the comparative transcriptome of PWNs after inoculation were analyzed with gene ontology (GO) enrichment. The GO functional analysis showed that the DEGs were significantly enriched in the cell membrane, transport activity, and metabolic process. These GO classes are believed to be related to the digestion and innate immunity of nematodes [41,42]. White et al. studied the interaction between Caenorhabditis elegans and S. maltophilia and found that the DEGs were significantly enriched in these GO categories, such as components of membrane, transport, oxidation, and reduction and metabolic process [43]. It was suggested that several DEGs in the comparative transcriptome of PWNs after inoculation might be related to the immunity of PWN.

KEGG classification was also performed to estimate the functions of the DEGs. We found that the DEGs between two PWN treatments were enriched in the Wnt, Rap1, PI3K Akt, cAMP, cGMP PKG, ECM-receptor, MAPK, and calcium signaling pathways. It has been reported that ECM-receptor interaction, Wnt, PI3K Akt, and MAPK signaling pathways play immunomodulatory roles when organisms interact with bacteria or fight against other stresses [44-47]. In the interaction between Meloidogyne incognita and bacteria, the expression of many genes involved in Wnt, PI3K Akt, MAPK, and other immune-related pathways, as well as cAMP, cGMP PKG, calcium, and other pathways changed significantly $[48,49]$. Compared with aseptic PWNs, it could be considered that the PWNs carrying bacteria changed significantly in various immune regulatory pathways after being inoculated pines. This also meant that $S$. maltophilia might affect the immune process of $B$. xylophilus in infected P. massoniana.

According to the analysis of the protein interactions of the DEGs, a number of key genes emerged from our study, including polyubiquitin gene, leucine rich repeated serine/threonine protein kinase gene, glyceraldehyde-3-phosphate dehydrogenase gene (GAPDH), acetyl CoA carboxylase gene, and heat shock protein gene. One of these genes, Acetyl CoA carboxylase gene of B. xylophilus is related to the propagation, migration, and movement behavior of B. xylophilus $[50,51]$. For the HSP genes, the proteins they encode are conserved and related to biotic and abiotic stresses [52,53]. Following interference with the HSP70 gene, the reproductive ability and amount of oviposition of B. xylophilus decrease [54]. The Hsp90 gene of $B$. xylophilus is necessary for maintaining body temperature and ensuring reproduction in nematodes [55]. However, little is known about other HSP genes of B. xylophilus, such as the Hsp 75 and Hsp 110 genes. Similarly, the functions of the ubiquitin genes, leucine-rich repetitive serine/threonine protein kinase genes, and GAPDH genes of B. xylophilus still need to be studied and verified. The ubiquitination pathway of nematodes could help them resist the infection of pathogenic factors [56-59]. Two ubiquitin genes of B. xylophilus were also cloned, but their functions remain to be further studied $[60,61]$. Leucine-rich repetitive serine/threonine protein kinase genes are often associated with plant resistance [62-64]. The glyceraldehyde-3-phosphate dehydrogenase gene $(\mathrm{GAPDH})$ is a gene with a wide range of functions, including gene expression control, membrane transport, cell signal transmission, interaction with RNA and other proteins, and avoidance of host 
immunity [65]. It was speculated that these key genes might affect the survival, reproduction, immunity, and many other processes of B. xylophilus, although their characterization remains to be explored.

In addition, many cell wall degrading enzyme genes, detoxification-related genes, and virulencerelated genes, for example, pectate lyase genes, cellulase genes, cytochrome p450 genes, and venom allergen-like protein genes, were differentially expressed under the two nematode treatments in our study. Cellulose, hemicellulose, and pectin are important components of the plant cell wall. B. xylophilus can secrete pectinase, and cellulase allows the colonization and migration of PWNs in pine [66-69]. Cytochrome P450 genes were associated with the vitality, reproduction, virulence, and detoxification of B. xylophilus [70,71]. The venom allergen-like protein gene was related to the migration, parasitism, and virulence of B. xylophilus [72]. The silencing of cathepsin L-cysteine protease genes in B. xylophilus reduces the feeding, reproduction, and virulence of $B$. xylophilus [73]. The glutathione S-transferase gene, $\mathrm{ABC}$ transporter gene, uridine diphosphate glucose transferase related gene, retinol dehydrogenase gene, carboxylesterase gene, etc., are also related to the reproduction and virulence of nematodes [39]. The number of these DEGs in nematodes after inoculation of pine was much greater than that in nematodes cultured on B. cinerea [21]. Therefore, it can be concluded that S. maltophilia may affect the invasion, parasitism, and virulence of B. xylophilus, whether on B. cinerea or in trees.

\section{Conclusions}

One of the most dominant bacteria in the B. xylophilus, S. maltophilia, can promote the propagation of nematodes and cause pine wilt disease faster. At the level of transcription, we found that 4240 genes were differentially expressed between aseptic B. xylophilus and B. xylophilus containing S. maltophilia after inoculation of aseptic P. massoniana. These differentially expressed genes were significantly enriched in some immune-related GO categories and KEGG pathways. The polyubiquitin-rich gene, leucine-rich repeat serine/threonine-protein kinase gene, and heat shock protein genes, etc., may play the key roles on immune resistance. In addition, S. maltophilia also make four cell wall hydrolase genes, and several detoxification- and pathogenesis-related protein genes differentially expressed. These results indicate that S. maltophilia can affect the expression of some pathogenesis- and immune-related genes, thus enhancing the virulence of B. xylophilus and aggravating the pine wilt disease.

Supplementary Materials: The following are available online at http://www.mdpi.com/1999-4907/11/9/908/s1, Table S1: Interaction between differentially expressed genes and proteins.

Author Contributions: Conceptualization, Q.X. and X.-Q.W.; data curation, Q.X. and F.W.; formal analysis, Q.X.; funding acquisition, X.-Q.W. and J.-R.Y.; investigation, Q.X.; methodology, Q.X. and X.-Q.W.; project administration, Q.X., X.-Q.W., and J.-R.Y.; resources, X.-Q.W. and J.-R.Y.; supervision, X.-Q.W. and J.-R.Y.; validation, Q.X. and X.-Q.W.; visualization, Q.X. and X.-Q.W.; writing—original draft, Q.X. and F.W.; and writing—review and editing, Q.X. and X.-Q.W. All authors have read and agreed to the published version of the manuscript.

Funding: This research was funded by National Key Research and Development Programme of China, grant number 2018YFD0600203, Jiangsu Provincial Agricultural Science and Technology Innovation Fund, grant number CX (16) 1005, the Priority Academic Programme Development of Jiangsu Higher Education Institutions (PAPD) and Innovation Plan for Graduate Students of Jiangsu, China, grant number KYZZ16_0315.

Acknowledgments: We are grateful to Long-Xi He, Jiangxi Forest Pest Control and Quarantine Bureau, Nanchang, China, for his comments and contributions to the manuscript.

Conflicts of Interest: The authors declare no conflict of interest. The funders had no role in the design of the study; in the collection, analyses, or interpretation of data; in the writing of the manuscript, or in the decision to publish the results.

\section{References}

1. Rautapaa, J. Experiences with Bursaphelenchus xylophilus in Finland. Eppo Bull. 1986, 16, 453-456. [CrossRef]

2. Mamiya, Y. History of pine wilt disease in Japan. J. Nematol. 1988, 20, 219-226. [PubMed]

3. Yi, C.K.; Byun, B.H.; Park, J.D.; Yang, S.I.; Chang, K.H. First finding of the pine wood nematode, Bursaphelenchus xylophilus (Steiner et Buhrer) Nickle and its insect vector in Korea. Res. Rep. For. Res. Inst. Seoul 1989, 3, 141-149. 
4. Zhou, L.F.; Chen, F.M.; Xie, L.Y.; Pan, H.Y.; Ye, J.R. Genetic diversity of pine-parasitic nematodes Bursaphelenchus xylophilus and Bursaphelenchus mucronatus in China. For. Path 2017, 47, e12334. [CrossRef]

5. Dong, Y.Q.; Pan, J.L.; Li, J.; Wang, Q.S.; Zhang, T.L.; Liu, H.T. Analysis of the research status and direction of Bursaphelenchus xylophilus based on domestic and foreign scientific and technological literature. For. Pest. Dis. 2020, 1-5. [CrossRef]

6. Nascimento, F.X.; Hasegawa, K.; Mota, M.; Vicente, C.S. Bacterial role in pine wilt disease development-Review and future perspectives. Environ. Microbiol. Rep. 2015, 7, 51-63. [CrossRef]

7. Chi, S.Y.; He, Y.Q.; Ben, A.L.; Han, Z.M. Comparison of thickness and content of soluble polysaccharose on the body surface of Bursaphelenchus xylophilus. J. Beijing For. Univ. 2008, 30, 175-178. [CrossRef]

8. Liu, K.C.; Zeng, F.L.; Ben, A.L.; Han, Z.M. Pathogenicity and repulsion for toxin-producing bacteria of dominant bacteria on the surface of American pine wood nematodes. J. Phytopathol. 2017, 165, 580-588. [CrossRef]

9. Nascimento, F.X.; Espada, M.; Barbosa, P.; Rossi, M.J.; Vicente, C.S.; Mota, M. Non-specific transient mutualism between the plant parasitic nematode, Bursaphelenchus xylophilus, and the opportunistic bacterium Serratia quinivorans BXF1, a plant-growth promoting pine endophyte with antagonistic effects. Environ. Microbiol. 2016, 18, 5265-5276. [CrossRef]

10. Li, Y.L.; Zheng, C.Y.; Liu, K.C.; Wu, Y.; Fan, B.; Han, Z.M. Transformation of multi-antibiotic resistant Stenotrophomonas maltophilia with GFP gene to enable tracking its survival on pine trees. Forests 2019, 10, 231. [CrossRef]

11. Kawazu, K.; Zhang, H.; Kanzaki, H. Accumulation of benzoic acid in suspension cultured cells of Pinus thunbergii Parl. in response to phenylacetic acid administration. Biosci. Biotechnol. Biochem. 1996, 60, 1410-1412. [CrossRef] [PubMed]

12. Vicente, C.S.L.; Nascimento, F.; Espada, M.; Barbosa, P.; Mota, M.; Glick, B.R.; Oliveira, S. Characterization of bacteria associated with pinewood nematode Bursaphelenchus xylophilus. PLoS ONE 2012, 7, e46661. [CrossRef] [PubMed]

13. Vicente, C.S.L.; Ikuyo, Y.; Mota, M.; Hasegawa, K. Pinewood nematode-associated bacteria contribute to oxidative stress resistance of Bursaphelenchus xylophilus. BMC Microbiol. 2013, 13. [CrossRef] [PubMed]

14. Cheng, X.Y.; Tian, X.L.; Wang, Y.S.; Lin, R.M.; Mao, Z.C.; Chen, N.; Xie, B.Y. Metagenomic analysis of the pinewood nematode microbiome reveals a symbiotic relationship critical for xenobiotics degradation. Sci. Rep. 2013, 3. [CrossRef]

15. Yuan, W.M.; Wu, X.Q.; Ye, J.R.; Tian, X.J. Observation by transmission electron microscope and identification of endophytic bacteria isolated from Bursaphelenchus xylophilus and B. mucronatus. Acta Microbiol. Sin. 2011, 51, 1071-1077. [CrossRef]

16. Xue, Q.; Xiang, Y.; Wu, X.Q.; Li, M.J. Bacterial communities and virulence associated with pine wood nematode Bursaphelenchus xylophilus from different Pinus spp. Int. J. Mol. Sci. 2019, 20, 3342. [CrossRef]

17. Xiang, Y.; Wu, X.Q.; Zhou, A.D. Bacterial diversity and community structure in the pine wood nematode Bursaphelenchus xylophilus and B. mucronatus with different virulence by high-throughput sequencing of the 16S rDNA. PLoS ONE 2015, 10, e0137386. [CrossRef]

18. Wu, X.Q.; Xue, Q.; Xiang, Y.; Ding, X.L.; Xu, X.L.; Ye, J.R. Community and functional diversity of bacteria associated with propagative and dispersal forms of Bursaphelenchus xylophilus. Nematology 2016, 18, 1185-1198. [CrossRef]

19. Wu, X.Q.; Yuan, W.M.; Tian, X.J.; Fan, B.; Fang, X.; Ye, J.R.; Ding, X.L. Specific and functional diversity of endophytic bacteria from pine wood nematode Bursaphelenchus xylophilus with different virulence. Int. J. Biol. Sci. 2013, 9, 34-44. [CrossRef]

20. He, L.X.; Xue, Q.; Wu, X.Q. Effects of endobacteria on reproduction and virulence of Bursaphelenchus xylophilus. J. Nanjing For. Univ. 2016, 40, 47-51. [CrossRef]

21. He, L.X.; Wu, X.Q.; Xue, Q.; Qiu, X.W. Effects of endobacterium (Stenotrophomonas maltophilia) on pathogenesis-related gene expression of pine wood nematode (Bursaphelenchus xylophilus) and pine wilt disease. Int. J. Mol. Sci. 2016, 17, 778. [CrossRef] [PubMed]

22. Baermann, G. Eine einfache methode zur auffindung von Ankylostomum (nematoden) larven in erdproben. Geneeskd. Tijdschr. Ned. Indie 1917, 57, 131-137.

23. Zhu, L.H.; Ye, J.; Negi, S.; Xu, X.L.; Wang, Z.L.; Ji, J.Y. Pathogenicity of aseptic Bursaphelenchus xylophilus. PLoS ONE 2012, 7, e38095. [CrossRef] [PubMed] 
24. Gresshoff, P.M.; Doy, C.H. Development and differentiation of haploid Lycopersicon esculentum (tomato). Planta 1972, 107, 161-170. [CrossRef]

25. Zhu, L.H.; Wu, X.Q.; Qu, H.Y.; Ji, J.; Ye, J.R. Micropropagation of Pinus massoniana and mycorrhiza formation in vitro. Plant. Cell Tiss. Organ. Cult. 2010, 102, 121-128. [CrossRef]

26. Yu, L.Z.; Wu, X.Q.; Ye, J.R.; Zhang, S.N.; Wang, C. NOS-like-mediated nitric oxide is involved in Pinus thunbergii response to the invasion of Bursaphelenchus xylophilus. Plant Cell Rep. 2012, 31, 1813-1821. [CrossRef]

27. Kikuchi, T.; Cotton, J.A.; Dalzell, J.J.; Hasegawa, K.; Kanzaki, N.; McVeigh, P.; Takanashi, T.; Tsai, I.J.; Assefa, S.A.; Cock, P.J.; et al. Genomic insights into the origin of parasitism in the emerging plant pathogen Bursaphelenchus xylophilus. PLoS Pathog. 2011, 7, e1002219. [CrossRef]

28. Daehwan, K.; Ben, L.; Salzberg, S.L. HISAT: A fast spliced aligner with low memory requirements. Nat. Methods 2015, 12, 357-360. [CrossRef]

29. Pertea, M.; Pertea, G.M.; Antonescu, C.M.; Chang, T.C.; Mendell, J.T.; Salzberg, S.L. StringTie enables improved reconstruction of a transcriptome from RNA-seq reads. Nat. Biotechnol. 2015, 33, 290-295. [CrossRef]

30. Trapnell, C.; Roberts, A.; Goff, L.; Pertea, G.; Kim, D.; Kelley, D.R.; Pimentel, H.; Salzberg, S.L.; Rinn, J.L.; Pachter, L. Differential gene and transcript expression analysis of RNA-seq experiments with TopHat and Cufflinks. Nat. Protoc. 2012, 7, 562-578. [CrossRef]

31. Kong, L.; Zhang, Y.; Ye, Z.Q.; Liu, X.Q.; Zhao, S.Q.; Wei, L.P.; Gao, G. CPC: Assess the protein-coding potential of transcripts using sequence features and support vector machine. Nucleic Acids Res. 2017, 35, W345-W349. [CrossRef] [PubMed]

32. Langmead, B.; Salzberg, S.L. Fast gapped-read alignment with Bowtie 2. Nat. Methods 2012, 9, 357. [CrossRef] [PubMed]

33. Li, B.; Dewey, C.N. RSEM: Accurate transcript quantification from RNA-Seq data with or without a reference genome. BMC Bioinform. 2011, 12, 323. [CrossRef] [PubMed]

34. Lokesh, K.; Matthias, E.F. Mfuzz: A software package for soft clustering of microarray data. Bioinformation 2007, 2, 5-7. [CrossRef]

35. Buchfink, B.; Xie, C.; Huson, D.H. Fast and sensitive protein alignment using DIAMOND. Nat. Methods 2015, 12, 59-60. [CrossRef]

36. Mering, C.V.; Jensen, L.J.; Snel, B.; Hooper, S.D.; Krupp, M.; Foglierini, M.; Jouffre, N.; Huynen, M.A.; Bork, P. STRING: Known and predicted protein-protein associations, integrated and transferred across organisms. Nucleic Acids Res. 2004. [CrossRef]

37. Shannon, P.; Markiel, A.; Ozier, O.; Baliga, N.S.; Wang, J.T.; Ramage, D.; Amin, N.; Schwikowski, B.; Ideker, T. Cytoscape: A software environment for integrated models of biomolecular interaction networks. Genome Res. 2003, 13, 2498-2504. [CrossRef]

38. Palleroni, N.J.; Bradbury, J.F. Stenotrophomonas, a new bacterial genus for Xanthomonas maltophilia (Hugh 1980) Swings et al. 1983. Int. J. Syst. Bacteriol. 1993, 43, 606-609. [CrossRef]

39. Qiu, X.; Wu, X.; Huang, L.; Tian, M.; Ye, J. Specifically expressed genes of the nematode Bursaphelenchus xylophilus involved with early interactions with pine trees. PLoS ONE 2013, 8, e78063. [CrossRef]

40. Tsai, I.J.; Tanaka, R.; Kanzaki, N.; Akiba, M.; Yokoi, T.; Espada, M.; Jones, J.T.; Kikuchi, T. Transcriptional and morphological changes in the transition from mycetophagous to phytophagous phase in the plant-parasitic nematode Bursaphelenchus xylophilus. Mol. Plant. Pathol. 2016, 17,77-83. [CrossRef]

41. Coolon, J.D.; Jones, K.L.; Todd, T.C.; Carr, B.C.; Herman, M.A. Caenorhabditis elegans genomic response to soil bacteria predicts environment-specific genetic effects on life history traits. PLoS Genet. 2009, 5, e1000503. [CrossRef] [PubMed]

42. Irazoqui, J.E.; Troemel, E.R.; Feinbaum, R.L.; Luhachack, L.G.; Cezairliyan, B.O.; Ausubel, F.M. Distinct pathogenesis and host responses during infection of C. elegans by P. aeruginosa and S. aureus. PLoS Pathog. 2010, 6, e1000982. [CrossRef] [PubMed]

43. White, C.V.; Herman, M.A. Transcriptomic, functional, and network analyses reveal novel genes involved in the interaction between Caenorhabditis elegans and Stenotrophomonas maltophilia. Front. Cell Infect. Microbiol. 2018, 8, 266. [CrossRef] [PubMed]

44. Zhang, Q.L.; Zhu, Q.H.; Liang, M.Z.; Wang, F.; Guo, J.; Deng, X.Y.; Chen, J.Y.; Wang, Y.J.; Lin, L.B. Comparative transcriptomic analysis provides insights into antibacterial mechanisms of Branchiostoma belcheri under Vibrio parahaemolyticus infection. Fish. Shellfish Immunol. 2018, 76, S1050464818301244. [CrossRef] [PubMed] 
45. Silva-Garcia, O.; Valdez-Alarcon, J.J.; Baizabal-Aguirre, V.M. The Wnt/beta-catenin signaling pathway controls the inflammatory response in infections caused by pathogenic bacteria. Mediat. Inflamm. 2014, 2014, 310183. [CrossRef] [PubMed]

46. Gami, M.S.; Wolkow, C.A. Studies of Caenorhabditis elegans DAF-2/insulin signaling reveal targets for pharmacological manipulation of lifespan. Aging Cell 2006, 5, 31-37. [CrossRef]

47. Kim, E.S.; Kim, M.S.; Moon, A. TGF-beta-induced upregulation of MMP-2 and MMP-9 depends on p38 MAPK, but not ERK signaling in MCF10A human breast epithelial cells. Int. J. Oncol. 2004, 25, 1375-1382. [CrossRef]

48. Zou, X.X.; Lu, Y.; Sun, Q.G.; Huang, H.Q.; Liu, M.; Bao, S.X. Transcriptome analysis of Meloidogyne incognita encumbered by Pasteuria penetrans endospores provides new insights into bacteria and nematode interaction. Nematology 2017, 19, 839-851. [CrossRef]

49. Phani, V.; Somvanshi, V.S.; Shukla, R.N.; Davies, K.G.; Rao, U. A transcriptomic snapshot of early molecular communication between Pasteuria penetrans and Meloidogyne incognita. BMC Genom. 2018, 19, 850. [CrossRef]

50. Sun, C.; Qi, W.J.; Zhang, M.A.; Zhang, P.; Liu, Z.Y.; Zhang, X.Y. The influence of drug intervention on acetylcholine to the movement behavior of Bursaphelenchus xylophilus. For. Pest. Dis. 2018, 37, 1-5. [CrossRef]

51. Xiong, Y.F. Molecular Cloning and Characterizatio of a New Acetylcholinesterse Gene Bx-Ace-2 From Pine Wood Nematode Bursaphelenchus Xylophilus and Its RNA Interference; Nanjing Agricultural University: Nanjing, China, 2009.

52. Feder, M.E.; Hofmann, G.E. Heat-shock proteins, molecular chaperones, and the stress response: Evolutionary and ecological physiology. Annu. Rev. Physiol. 1999, 61, 243-282. [CrossRef] [PubMed]

53. Sifri, C.D.; Begun, J.; Ausubel, F.M.; Calderwood, S.B. Caenorhabditis elegans as a model host for Staphylococcus aureus pathogenesis. Infect. Immun. 2003, 71, 2208. [CrossRef] [PubMed]

54. Zhen, J.Y. Isolated of the Heat Shock Transcription Factor (HSF) and Analysis HSP70 by RNAi in Bursaphelenchus Xylophilus; Hunan Agricultural University: Changsha, China, 2008.

55. Wang, F.; Wang, Z.; Li, D.; Chen, Q. Identification and characterization of a Bursaphelenchus xylophilus (Aphelenchida: Aphelenchoididae) thermotolerance-related gene: Bx-HSP90. Int. J. Mol. Sci. 2012, 13, 8819-8833. [CrossRef] [PubMed]

56. Perrett, C.A.; Lin, D.Y.; Zhou, D. Interactions of bacterial proteins with host eukaryotic ubiquitin pathways. Front. Microbiol. 2011, 2, 143. [CrossRef]

57. Staff, T.P.P. Correction: Ubiquitin-mediated response to microsporidia and virus infection in C. elegans. PLoS Pathog. 2014, 10, e1004200. [CrossRef]

58. Cohen, L.B.; Troemel, E.R. Microbial pathogenesis and host defense in the nematode C. elegans. Curr. Opin. Microbiol. 2015, 23, 94-101. [CrossRef]

59. Melo, J.A.; Ruvkun, G. Inactivation of conserved C. elegans genes engages pathogen- and xenobiotic-associated defenses. Cell 2012, 149, 452-466. [CrossRef]

60. Wang, B.Y.; Wang, F.; Liu, L.H.; Ma, L.; Hu, Q.D.; Liang, W.Y.; Gao, W. Gene cloning and structures implications of an Rbx1 enzyme from Bursaphelenchus xylophilus. J. Northeast For. Univ. 2013, 41, 123-126. [CrossRef]

61. Xu, J.Y.; Chen, Q.L.; Zhang, R.Z.; Li, D.L. Genetic cloning of Bx-ubc-3 and identification of ubiquitin pathway from Bursaphelenchus xylophilus (Aphelenchida: Aphelenchoididae). Forest Eng. 2019, 35, 9-15. [CrossRef]

62. Lu, X.H.; Huang, J.L.; Liu, Z.M.; Qin, B.X.; Qiao, L.Y. Detection of NBS-LRR type disease resistance gene in the resistance cultivars of tomato to Meloidogyne incognita. J. Huazhong Agr. Univ. 2012, 31, 208-211.

63. Xie, H.; Chen, X.Q.; Zhu, L.; Jia, Y.H.; Yao, L.; Cui, C.S.; Ma, R.C. cDNA cloning of an leucine-rich repeats(LRR)-like disease resistance protein gene $B C L R R$ from Chinese cabbage and its functional analysis in mediating plant resistance to soft-rot disease. J. Agric. Biotechnol. 2010, 18, 416-423. [CrossRef]

64. Yang, D.W.; Wang, M.; Han, L.B.; Tang, D.Z.; Li, S.P. Progress of cloning and breeding application of blast resistance genes in rice and avirulence genes in blast fungi. Chin. Bull. Bot. 2019, 54, 265-276. [CrossRef]

65. Perez-Casal, J.; Potter, A.A. Glyceradehyde-3-phosphate dehydrogenase as a suitable vaccine candidate for protection against bacterial and parasitic diseases. Vaccine 2016, 34, 1012-1017. [CrossRef] [PubMed]

66. Ma, H.B.; Liang, J.; Lv, Q.; Zhang, X.Y. Study on cellulase dispersal ability from Bursaphelenchus xylophilus and B. mucronatus. For. Res. 2009, 22, 397-400. 
67. Kikuchi, T.; Shibuya, H.; Aikawa, T.; Jones, J.T. Cloning and characterization of pectate lyases expressed in the esophageal gland of the pine wood nematode Bursaphelenchus xylophilus. Mol. Plant. Microbe Interact. 2006, 19, 280-287. [CrossRef] [PubMed]

68. Valadas, V.; Laranjo, M.; Mota, M.; Oliveira, S. Molecular characterization of Portuguese populations of the pinewood nematode Bursaphelenchus xylophilus using cytochrome b and cellulase genes. J. Helminthol. 2013, 87, 457-466. [CrossRef]

69. Qiu, X.W.; Wu, X.Q.; Huang, L.; Ye, J.R. Influence of Bxpel1 gene silencing by dsRNA interference on the development and pathogenicity of the pine wood nematode, Bursaphelenchus xylophilus. Int. J. Mol. Sci. 2016, 17, 125. [CrossRef]

70. Lindblom, T.H.; Dodd, A.K. Xenobiotic detoxification in the nematode Caenorhabditis elegans. J. Exp. Zool. A Comp. Exp. Biol. 2006, 305, 720-730. [CrossRef]

71. Xu, X.L.; Wu, X.Q.; Ye, J.R.; Huang, L. Molecular characterization and functional analysis of three pathogenesis-related cytochrome P450 genes from Bursaphelenchus xylophilus (Tylenchida: Aphelenchoidoidea). Int. J. Mol. Sci. 2015, 16, 5216-5234. [CrossRef]

72. Kang, J.S.; Koh, Y.H.; Moon, Y.S.; Lee, S.H. Molecular properties of a venom allergen-like protein suggest a parasitic function in the pinewood nematode Bursaphelenchus xylophilus. Int. J. Parasitol. 2012, 42, 63-70. [CrossRef]

73. Xue, Q.; Wu, X.Q.; Zhang, W.J.; Deng, L.N.; Wu, M.M. Cathepsin L-like cysteine proteinase genes are associated with the development and pathogenicity of pine wood nematode, Bursaphelenchus xylophilus. Int. J. Mol. Sci. 2019, 20, 215. [CrossRef] [PubMed]

(C) 2020 by the authors. Licensee MDPI, Basel, Switzerland. This article is an open access article distributed under the terms and conditions of the Creative Commons Attribution (CC BY) license (http://creativecommons.org/licenses/by/4.0/). 